\title{
Argiloterapia associada em procedimentos estéticos
}

O estudo objetiva analisar os benefícios da argila em procedimentos estéticos. Para tanto, torna-se essencial o estudo da Geoterapia com ênfase nas funções e benefícios que cada tipo de argila proporciona quando aplicadas em tratamentos estéticos. A argila é utilizada desde a antiguidade para limpeza de pele e como máscaras para conservar e destacar a pele no rosto, sua utilização é abrangente e seus resultados são positivos se usada frequentemente de forma correta de acordo com a necessidade e o objetivo do tratamento. $\mathrm{O}$ artigo foi desenvolvido a partir de uma pesquisa do tipo exploratória bibliográfica, caracterizada como revisão, com busca nas bases de dados científicas Lilacs e Scielo, no período de 2006 até o ano de 2018. De acordo com a pesquisa a argila pode ser utilizada como um complemento em procedimentos estéticos, pois potencializa benefícios, tanto para a estética facial, como corporal, sendo que cada tipo de argila age de uma determinada forma, conforme desenvolvido na presente pesquisa.

Palavras-chave: Argila; Estética; Derme; Tecido.

\section{Associated clay therapy in aesthetic procedures}

The study aims to analyze the benefits of clay in procedures aesthetic. Therefore, the study of geotherapy with emphasis on functions and benefits that each type of clay provides when applied in aesthetic treatments. Clay has been used since ancient times for skin cleansing. And as masks to preserve and highlight the skin on the face, their use is results are positive if often used correct according to the need and purpose of the treatment. The article was developed from a bibliographic exploratory research, characterized as a review, searching the scientific databases Lilacs and Scielo, from 2006 to 2018. According to research can be used as a complement in aesthetic procedures because potentiates benefits for both facial and body aesthetics. Type of clay acts in a certain way as developed in the present search.

Keywords: Clay; Aesthetics; Dermis; Fabric.

Topic: Dermatologia

Reviewed anonymously in the process of blind peer.
Received: $19 / 10 / 2020$

Approved: 20/01/2021
Rubia de Souza Oliveira Matola

Centro Universitário Luterano de Palmas, Brasil

http://lattes.cnpq.br/5000166538882558

rubia.olive@hotmail.com

\section{Deuselândia de Sá}

Centro Universitário de Anápolis, Brasil

http://lattes.cnpq.br/8177451592771132

saborgesrocha@hotmail.com

\section{Referencing this:}

MATOLA, R. S. O.; SÁ, D.. Argiloterapia associada em procedimentos estéticos. Scire Salutis, v.11, n.1, p.46-53, 2021. DOI:

http://doi.org/10.6008/CBPC2236-9600.2021.001.0005 


\section{INTRODUÇÃO}

Ser eternamente jovem e retardar o envelhecimento são uma busca constante pelas mulheres, a indústria das mulheres, a indústria da cosmética utiliza e renova a cada dia, tecnologia em prol da beleza, desta forma, o uso de equipamentos eletroterápicos vem crescendo e ganhando força no que diz respeito a estimulação de fibras e proteínas fundamentais para o rejuvenescimento facial, onde a derme é o foco dos tratamentos.

O processo de envelhecimento se baseia na conjunção de fenômenos ambientais e genéticos aos quais o indivíduo está sujeito ao longo da vida e que fazem variar e diferenciar sua medida cronológica (tempo de vida em anos) e biológica (sua capacidade funcional), tanto para si como para outros indivíduos da mesma espécie. Isso significa dizer que, muitas vezes, a idade cronológica não combina com a fisiológica. Logo, surge o conceito que afirma que cada indivíduo passa por um processo de envelhecimento único (EVELINE, 2010).

Diante do contexto, o objetivo deste artigo é identificar e analisar estudos, pesquisar e confrontar ideias e resultados na utilização da RF na redução de rugas. O estudo constitui-se de uma pesquisa bibliográfica, dirigida a trabalhos publicados que se mostraram adequados a responder à seguinte questão norteadora: Quais os efeitos da Radiofrequência na redução de rugas na região facial? Conclui-se que a RF vem sendo um recurso capaz de reduzir nas rugas faciais melhorar o tecido da pele, retardando o envelhecimento.

\section{REVISÃO TEÓRICA}

O envelhecimento é um processo natural do ser humano e que cada um tem o seu tempo, o seu relógio e os seus marcadores, envolvendo a qualidade de vida, o meio em que vive as condições culturais e sociais em que está inserido. Conhecer as manifestações fisiológicas do envelhecimento é fundamental para aqueles que trabalham na saúde pública, importante para subsidiar a criação de estratégias que possam promover a qualidade de vida do idoso e tranquilidade à família que o assiste, objetivando mantê-lo o mais independente possível, garantindo sua participação na sociedade e respeitando as limitações impostas pelo envelhecimento (NUNES, 2007).

Há várias teorias para descrever o processo de envelhecimento, entre elas a estocástica, ligada ao acúmulo de danos moleculares, e a sistêmica, na qual o ambiente interage com os genes do indivíduo. Ocorre por fatores intrínsecos como envelhecimento cronológico, onde as células vão perdendo suas capacidades de renovação, esse é um fator inevitável e extrínsecos podendo ser retardados, controlado através de uma boa alimentação, qualidade de vida e principalmente a proteção contra os raios UVA e UVB que são responsáveis pela foto envelhecimento.

A Radiofrequência no tratamento de Flacidez Facial é um equipamento eletroterápico utilizado em estética que emite ondas eletromagnéticas que agem nas camadas mais profundas da pele, derme papilar e reticular, e produzem uma retração de colágeno através de seu aquecimento, assim promovem sua 
modelação e melhoram sua flacidez cutânea com o aumento da circulação sanguínea na região e como efeito tardio, estimulam os fibroblastos que tendem a sintetizar novas células de colágeno, resultando em uma pele mais hidratada, firme e com diminuição das linhas.

Com o passar dos anos, o corpo sofre alterações em todas as suas estruturas há uma perda de elasticidade colágeno e fibras elásticas da pele, tais modificações desempenham um papel importante no processo do envelhecimento. $O$ rosto é o primeiro a repercutir os sinais de envelhecimento: o conteúdo do tecido subcutâneo diminui consideravelmente principalmente na fronte, nas áreas pré-molares e perioral, a musculatura torna-se hipotrófica, acentuando a queda e a perda da elasticidade, o aparecimento de rugas, discromias e lesões, a pele torna-se mais fina desidratada e seca.

A busca por tratamentos estéticos cresce como nunca ultimamente através da utilização de cosméticos, cirurgias plásticas e eletroterapias, entre elas a Radiofrequência (RF), este processo tem sido usado como recurso no tratamento estético das rugas, rejuvenescimento e flacidez tecidual (DAL GOBBO, 2010).

A Radiofrequência aquece os tecidos e promove a formação de um novo colágeno, reduzindo as rugas. Cujo método não ablativo obtiveram satisfação parcial nas rugas faciais como nas regiões orbicular dos olhos, boca e contorno facial. As causas da flacidez de pele, os tipos de flacidez de pele que existem, as principais características da pele flácida, e alguns tratamentos promissores. Sabe-se que o processo de envelhecimento é dinâmico e imutável e que atinge todos os sistemas do organismo.

Nesta fase vão surgindo inúmeras alterações da pele, e uma delas é a flacidez tissular. Geralmente, os casos de flacidez cutânea não vêm isolados e sim com algum grau de flacidez muscular associado e, ao mesmo tempo, devido à vida atribulada de muitas pessoas, que ficam sem tempo para a prática de atividades físicas, perdendo assim força e trofismo muscular. Mas a flacidez de pele pode vir por outros motivos que não sejam o envelhecimento, e piorar neste processo da vida.

Alguns aspectos moleculares da flacidez de pele, conhecida também como flacidez cutânea. A pele (derme) contém células chamadas fibroblastos, que têm a função de sintetizar as proteínas colágenas e elásticas, responsáveis respectivamente pela sustentação e elasticidade da nossa pele. Essas proteínas são fibrosas, formando fibras insolúveis, constituindo cerca de $25 \%$ da massa proteica total.

A síntese, a regulação e reprodução proteica realizadas pelos fibroblastos são determinadas pelos hormônios e pelos fatores de crescimento existentes. Os fatores de crescimento que são produzidos pelas plaquetas do sangue se ligam a receptores da membrana celular, regulando a atividade da célula. Então, uma pessoa com pequena quantidade de fatores de crescimento (que são proteínas que ficam na membrana plasmática do fibroblasto) terá dificuldade de produzir colágeno e elastina, ou produzirá em menor quantidade.

Ressalva que o colágeno é uma proteína básica que se encontra na matriz extracelular e nos tecidos conectivos, representado por cerca de $30 \%$ das proteínas no corpo humano.

Para Arthur et al. (2012) o colágeno se produz pelo organismo desde o nascimento, exercendo muitas funções, entre elas a de unir e fortalecer os tecidos. Com o envelhecimento ele muda tanto na qualidade 
quanto na qualidade. Essa redução da quantidade de colágeno no tecido epitelial deve-se à diminuição da atividade metabólica dos fibroblastos.

\section{MATERIAIS E MÉTODOS}

O estudo constitui-se de uma pesquisa bibliográfica, dirigida a trabalhos publicados que se mostraram adequados a responder à seguinte questão norteadora: Qual a eficácia da argiloterapia no rejuvenescimento facial? A revisão integrativa é um método que tem o objetivo de sintetizar os resultados obtidos nas pesquisas sobre um determinado tema, sistematicamente, a fim de contribuir para o conhecimento sobre este tema.

A revisão integrativa inclui a análise de pesquisas relevantes que dão suporte para a tomada de decisão e a melhoria da prática clínica, possibilitando a síntese do estado do conhecimento de um determinado assunto, além de apontar lacunas do conhecimento que precisam ser preenchidas com a realização de novos estudos.

Esta pesquisa consiste em uma revisão sistemática de literaturas e estudos que abordem o tema 'Argiloterapia Associada em Procedimentos Estéticos'. Sendo também de natureza exploratória, pois objetivou ter maior familiaridade com o problema levantado. Para Gil (2010), essas pesquisas têm o objetivo de proporcionar maior familiaridade com o problema, tornando-o mais explícito de forma a aprimorar ideias, ou a descobertas de intuições.

De caráter bibliográfico, pois foram obtidas informações bibliográficas e selecionados documentos relacionados aos objetivos. A pesquisa bibliográfica é um estudo sistemático, embasado em materiais já publicados em veículos como livros, revistas (periódicos) e documentários.

A presente revisão sistemática foi realizada a fim de avaliar e resumir criticamente os estudos relevantes sobre o tema em questão que o conhecimento adquirido na investigação contribua para as prevenções e a melhoria na prática do tratamento do rejuvenescimento através da Argiloterapia.

A metodologia desenvolvida permite que as informações extraídas dos estudos básicos pesquisados e avaliados sejam transformadas e aplicadas em conhecimentos científicos a fim de permitir uma melhor visão sobre os efeitos da Argiloterapia como recurso eficaz na melhoria da textura da pele.

\section{Critérios para escolha do material}

O material do estudo foi constituído em livros, periódicos e revistas, nas seguintes bases de dados: Biblioteca virtual e bases eletrônicas disponíveis em: (a) SCIELO: A biblioteca cientifica eletrônica em linha (scielo) é produto da cooperação entre FAPESP (Fundação de Amparo à Pesquisa de Estado de São Paulo), a BIREME, instituições nacionais e internacionais relacionadas com comunicação cientifica e editores científicos. (b) BVS: A Biblioteca Virtual da Saúde permite acesso livre e gratuito à informação técnica cientifica gerada por instituições acadêmicas e pelo Sistema Único de Saúde do Brasil. 


\section{RESULTADOS E DISCUSSÃO}

Observa-se após essa revisão dos artigos publicados, que apesar do uso da argila desde muitos anos atrás, a execução e publicação de artigos ainda é muito pequena, fazendo com que a elaboração deste estudo não contenha muitas informações a respeito da argila.

Alguns estudos contemplam a composição da argila e os tipos existentes. Segundo Machado et al. (2018), as argilas contêm Silício (Si), Alumínio (Al), Ferro (Fe), Zinco (Zn), Magnésio (Mg), Cálcio (Ca), Potássio (K) e Titânio (Ti).

Argilas são materiais naturais, terrosos, de granulação fina apresentando partículas com diâmetro geralmente inferior a $2 \mu \mathrm{m}$ e constituída quimicamente por silicatos hidratados de alumínio, ferro e magnésio. São constituídas por partículas cristalinas extremamente pequenas, de um número restrito de minerais conhecidos como argilominerais (BARBOZA et al., 2006).

As argilas esmectitas são materiais constituídos por um, ou mais, argilominerais esmectíticos e por alguns minerais acessórios (principalmente quartzo, cristobalita e micas). Os argilominerais esmectíticos caracterizam-se por apresentarem, dentro de sua estrutura cristalográfica, o alumínio ou magnésio substituído parcial ou totalmente por Mg2+, Fe3+ e outros cátions (FERREIRA et al., 2009).

As argilas esmectíticas podem ser mono-catiônicas ou poli-catiônicas, com predominância de um cátion ou não. As esmectitas brasileiras são normalmente policatiônicas, sendo geralmente cálcio e magnésio como cátions predominantes. A única esmectita brasileira contendo grande quantidade de sódio como cátion trocável é a do município de Boa Vista (FERREIRA et al., 2009).

Cada elemento contido na argila age sobre a pele de acordo com suas características. Sendo assim, o elemento ferro age como um antisséptico e como um catalisador de renovação celular; o silício como fornecimento de reconstrução de tecidos da pele, hidratação e efeito calmante; zinco e magnésio são revigorantes; cálcio e potássio agem na circulação e fortalecimento do tecido; o titânio tem característica de foto proteção, sendo assim um mineral capaz de refletir a radiação ultravioleta-UV (MACHADO et al., 2018).

Alguns compostos ativos de argila podem ter um efeito terapêutico na saúde das pessoas. A caolinita (mineral presente na maioria das argilas) contém um 7 efeito anti-inflamatório. Neste estudo foi usada a argila medicinal cinzenta que contém 49\% de SiO2 (dióxido de silício) e 14\% de Al2O3 (alumina), composição semelhante aos encontrados em argila de Ocaya (existente no Brasil), são concentrações não apropriadas de uma argila medicinal, por possuir alta concentrações de sílica, onde pode agir reabsorvendo metais pesados.

Araujo et al. (2018) afirmam que as argilas são constituídas por argilominerais que apresentam estrutura em camadas com espessura na escala nanométrica (alta área superficial). Esses materiais apresentam cátions que podem ser trocados para facilitarem a interação com outro material. As argilas apresentam as mesmas características por se tratarem de montmorilonitas que é o seu principal argilomineral.

Os principais fatores que controlam as propriedades das argilas são a composição mineralógica dos argilominerais e dos não argilominerais bem como, as distribuições granulométricas das suas partículas, teor 
em eletrólitos dos cátions trocáveis e sais solúveis, natureza e teor de componentes orgânicos e características de consistência da argila. Seja qual for a argila, essa pode ser composta por um único argilomineral ou por vários e podem conter ainda matéria orgânica, sais solúveis, partículas de quartzo, pirita, calcita, outros minerais residuais e minerais amorfos (BARBOZA et al., 2006).

As argilas encontradas nos solos são utilizadas na fabricação de uma grande série de produtos. Entretanto, é de se esperar produtos com propriedades bem diversificadas devido às particularidades. Em geral, a matéria prima, é uma mistura complexa de diferentes variedades mineralógicas, que se apresentam como 10 partículas de tamanho, forma e propriedades físicas e químicas diferentes. Concluísse então que, a composição química e mineralógica dos solos, a sua distribuição granulométrica e características são fatores que determinam a sua possível utilização. Diversas são as técnicas experimentais utilizadas para a caracterização mineralógica dos solos (BARBOZA et al., 2006).

Ainda, existem estudos que relatam que a aplicação da argila responde positivamente no alívio e tratamento em casos de contusões, esforço físico excessivo, má postura, doenças, enfermidades degenerativas, processos inflamatórios desintoxicação, tratamento de ferimentos, lesões superficiais revitalização do corpo, processos dérmicos e digestivos, distúrbios circulatórios e linfáticos, desequilíbrios geniturinários e respiratórios, quadros de estresse cardiopatias, lesões ou traumas musculares (MEDEIROS, 2013).

A argila possui importantes propriedades cosméticas, no momento em que é utilizada um sistema de troca entre a pele e os elementos da argila, acontece por meio da permeação dos oligoelementos na pele devido à capacidade de troca de cátions das argilas, e também pela água, que é absorvida pelos queratinócitos, que geram uma troca iônica de íons e facilitam a entrada nos espaços intersticiais das células da derme e epiderme, auxiliam na respiração celular e transferência de elétrons (MEDEIRO et al., 2013).

Na antiguidade, a argila já utilizada com fins terapêuticos pelos egípcios e os gregos, que aplicavam a argila para a limpeza da pele. Cleópatra, conhecida como a antiga deusa egípcia, utilizava máscaras de argila para conservar e destacar a pele do rosto. Mas acreditava-se que foi Pompeia, mulher de Nero, quem desenvolveu a máscara facial para conservar a pele contra a ação do sol e de agressões diárias (LOPES, 2014).

A argila é muito utilizada para fins estéticos, mas há documentos que indicam que na antiguidade o uso da argila já tinha prescrições para fins medicinais. Cita-se que ela teve destaque e grande emprego entre os médicos gregos, árabes e romanos, como Dioscórides, Avicena, Galeno e Plínio. Atualmente apesar dos avanços tecnológicos, as utilizações dos princípios ativos naturais inclusive os da argila, estão presentes na maioria das formulações cosméticas (AMORIM et al., 2012).

A argila também é utilizada para tratamento de acne do tipo não inflamatória, que utiliza a argila verde para amenizar o aspecto de oleosidade, revigorar a pele, age como agente de limpeza profunda, ação tonificante, adstringente, hidratante e cicatrizante (FERRARI, 2012).

Para tratamento de sardas, a argila é indicada por ser um método não invasivo como os peelings químicos e outros clareadores e despigmentantes. A sarda atinge pessoas com o fototipo l e ll por possuírem pele clara e sensível à luz solar. A argila branca tem propriedade clareadora e pode ser encontrada em 
formulação como máscara facial, de fácil acesso no mercado de cosméticos. Além de clareadora é cicatrizante, absorvente de oleosidade e traz um aspecto saudável à pele e rejuvenesce (GONÇALVES, 2012).

A eficácia do tratamento da argiloterapia pode ser potencializada com a associação a outros métodos terapêuticos, para produzir um efeito mais eficaz, é o que chamamos de mecanismos potencializadores e destacamos entre vários, a utilização de óleo essencial (LIMAS et al., 2010).

Cada argila possui sua particularidade quanto aos fins terapêuticos, as cores são fatores contribuintes para esta diferenciação. Para a utilização da argila correta depende da avaliação de um profissional que indicará a cor correta a ser utilizada, bem como a necessidade de utilizar-se sinergias para o objetivo do tratamento (MEDEIROS, 2013).

Portanto, as argilas possuem ações terapêuticas que são: antisséptica, analgésica, desintoxicante, mineralizante, equilibradora térmica e energética, anti-inflamatória, bactericida e cicatrizante.

\section{CONCLUSÕES}

A utilização da argila em procedimentos estéticos faciais e corporais tem recebido atenção especial nas áreas da cosmetologia e da medicina estética, devido suas inúmeras propriedades, sendo aplicadas para tratamentos de pele.

Ainda, há estudos que registram o uso de máscaras de argilas, como práticas terapêuticas na civilização egípcia, não sendo, portanto, um procedimento novo. Assim, apesar dos avanços e tecnologias utilizados no ramo estético, os profissionais dessa área procuram aliados naturais para melhor desempenho de seus tratamentos, por exemplo, cita-se a utilização da argila através da Geoterapia.

A Geoterapia é um tratamento que possui inúmeros benefícios à saúde e à estética da pele, possui propriedades antissépticas, cicatrizantes, anti-inflamatórias, esfoliantes, hidratantes, refrescantes, desintoxicantes, entre outros benefícios.

Por fim, a partir da revisão bibliográfica realizada, buscou-se na base de dados Lilacs e Scielo artigos sobre a temática proposta, sendo encontrado pouquíssimo material, assim, compreende-se que são necessárias outras pesquisas sobre os benefícios da argila no ramo estético e na produção de cosméticos.

\section{REFERÊNCIAS}

AMORIM, M. I.; PIAZZA, F. C. P.. O uso das argilas na estética facial e corporal. Itajaí: Universidade do Vale do Itajaí, 2012.

ARAUJO, B. A.; ARAUJO, E. M.; FERNANDES, P. M.; SANTOS FILHO, E. A.; MEDEIROS, K. M.. Membranas de polisulfona/argila: influência de diferentes argilas na propriedade de barreira, 2018.

ARTHUR, K.; NASCIMENTO, L. C.; FIGUEIREDO, D. A. S.; SOUZA, L. B.. Efeitos da geoterapia e fitoterapia associadas à cinesioterapia na osteoartrite de joelho: estudo randomizado duplo cego. Acta Fisiátrica, São Paulo, v.19, n.1, p.11-15, 2012. DOI: http://doi.org/10.5935/01047795.20120003
BARBOSA, R.; ARAÚJO, E. M.; MELO, T. J. A.; OLIVEIRA, A. D. Efeitos de Sais Quaternários de amônio na ornagofilização de uma argila bentonita nacional, 2006.

DAL GOBBO, P.. Estética facial essencial. São Paulo: Atheneu, 2010

EVELINE, C.. Máscaras: as estrelas da cosmetologia. Bel Col, São Paulo, n.52, p.22-24, 2010

FERRARI, I. G.. Tratamento da acne do tipo não inflamatória com argila verde. Três corações: Universidade Vale do Rio Verde, 2012.

FERREIRA, H. C.; KIMINAMI, R. H. G. A.; MENEZES, R. R.; NEVES, G. A.; SANTANA, L. N. L.; SOUTO, P. M.. Argilas 
bentoníticas de Cubati, Paraíba, Brasil: Caracterização física-mineralógica. 2009.

GIL, A. C.. Como elaborar projetos de pesquisa. 5 ed. São Paulo: Atlas, 2010.

GONÇALVES, L. H. V.. Avaliação dos efeitos da argila branca no clareamento das efélides. Três Corações: Universidade Vale do Rio Verde, 2012

LIMAS, J. R.; DUARTE, R.; MOSER, D. K.. A Argiloterapia: uma nova alternativa para tratamentos contra seborreia, dermatite seborreica e caspa. 2010.

LOPES, L. F. M.. Argilas medicinais: potencial simbólico e propriedades terapêuticas das argilas em suas diversas cores. Núcleo GRA: Geoterapia, Reflexologia e Acupuntura, 2014.

MACHADO, M. C. P.; LANGBEHN, J. T.; OLIVEIRA, C. M.; ELYSEU, F.; CARGNIN, M.; NONI JUNIOR, A.; FIZON, T. E. A..
Estudo do comportamento e caracterização de argilas bentoníticas após processo de liofilização. Cerâmica, v.64, n.370, p.207- 213, 2018. DOI: https://doi.org/10.1590/036669132018643702324

MEDEIRO, S. A.; LANZA, M. V. S.. Ação das argilas em tratamentos estéticos: revendo a literatura. Cadernos de Estudos e Pesquisas, v.17, n.38, 2013

MEDEIROS, G. M. S.. O poder da argila medicinal: princípios teóricos, procedimentos terapêuticos e relatos de experiências clínicas. Blumenau: Nova Letra, 2013.

NUNES, D. P. R.. Geoterapia: uma possibilidade no tratamento das sequelas da radiação ionizante no tratamento do câncer. Florianópolis: Universidade do Sul de Santa Catarina, 2007.

TOYOKI, B. K.; OLIVEIRA, A. C. T.. Argiloterapia: levantamento dos constituintes e utilizações dos diferentes tipos de argila. 2015.

A CBPC - Companhia Brasileira de Produção Científica (CNPJ: 11.221.422/0001-03) detém os direitos materiais desta publicação. Os direitos referem-se à publicação do trabalho em qualquer parte do mundo, incluindo os direitos às renovações, expansões e disseminações da contribuição, bem como outros direitos subsidiários. Todos os trabalhos publicados eletronicamente poderão posteriormente ser publicados em coletâneas impressas sob coordenação da Sustenere Publishing, da Companhia Brasileira de Produção Científica e seus parceiros autorizados. Os (as) autores (as) preservam os direitos autorais, mas não têm permissão para a publicação da contribuição em outro meio, impresso ou digital, em português ou em tradução. 